\title{
Chinese kindergartners' automatic processing of numerical magnitude in Stroop-like tasks
}

\author{
Xinlin Zhou and Yao Chen \\ Beijing Normal University, Beijing, China \\ Chuansheng Chen \\ University of California, Irvine, California \\ AND \\ Ting Jiang, Hongchuan Zhang, And QI Dong \\ Beijing Normal University, Beijing, China
}

\begin{abstract}
Using Stroop-like tasks, this study examined whether Chinese kindergartners showed automatic processing of numerical magnitude. A total of 36 children (mean age $=5$ years 10 months) were asked to perform physical size comparison (i.e., "Which of two numbers is bigger in physical size?") and numerical magnitude tasks (i.e., "Which of two numbers is bigger in numerical magnitude?") on 216 number pairs. These number pairs varied in levels of congruence between numerical magnitude and physical size (for Stroop effect) and numerical distance (for distance effect). On the basis of analyses of response time and error rates, we found that Chinese kindergartners showed automatic processing of numerical magnitude. These results are significantly different from previous studies' findings about the onset age (ranging from around the end of first grade to third grade) for automatic processing of numerical magnitude.
\end{abstract}

The processing of numerical magnitude can be either intentional or automatic (Girelli, Lucangeli, \& Butterworth, 2000; Noël, Rousselle, \& Mussolin, 2005). Intentional processing of numerical magnitude occurs when subjects are directed to attend to the magnitude of number(s) (e.g., "Which of two numbers is bigger in magnitude?"; see, e.g., Butterworth, 1999; Moyer \& Landauer, 1967). Automatic processing of numerical magnitude occurs when subjects are specifically asked to process nonmagnitude information about numbers (e.g., physical size), but there is evidence of the impact of numerical magnitude (e.g., magnitude information facilitates physical size judgment; Girelli et al., 2000; Noël et al., 2005). Various tasks have been used to study automatic processing of numbers. They include parity judgment (i.e., whether a number is odd or even; see, e.g., Berch, Foley, Hill, \& Ryan, 1999; Dehaene, Bossini, \& Giraux, 1993; Fias, Brysbaert, Geypens, \& d'Ydewalle, 1996), phonetic judgment (i.e., whether a number word has a particular vowel; Fias et al., 1996), identity judgment (i.e., whether two numbers are the same or different; see, e.g., Dehaene \& Akhavein, 1995; Duncan \& McFarland, 1980), and Stroop-like tasks (e.g., "Which number is bigger in physical size? 3 or 2?"; see, e.g., Besner \& Coltheart, 1979; Dehaene, 1997; Henik \& Tzelgov, 1982; Schwarz \& Heinze, 1998; Tzelgov, Meyer, \& Henik, 1992).
In Stroop-like tasks, subjects are asked to make comparisons of pairs of numbers that vary in numerical magnitude and physical size. There are three types of trials: congruent trials (e.g., " 2 " and " 3 ," in which 3 is bigger than 2 in both numerical magnitude and physical size); incongruent trials (e.g., " 2 " and " 3 "); and neutral trials (i.e., the pairs of numbers have either the same numerical magnitude or the same physical size, depending on the task). Subjects are asked to perform two kinds of comparisons - physical size comparison (i.e., "Which of the two numbers is bigger in physical size?") and numerical magnitude comparison (i.e., "Which of the two numbers is bigger in numerical magnitude?"). Typical results show that subjects take less time and make fewer errors during congruent trials than during incongruent trials (see, e.g., Besner \& Coltheart, 1979; Henik \& Tzelgov, 1982; Schwarz \& Heinze, 1998; Tzelgov et al., 1992). The size congruity effect during the physical size comparison tasks indicates that the numerical magnitude of a number is automatically activated to facilitate (under the congruent condition) or to interfere with (under the incongruent condition) the physical size comparison task. Similarly, a size congruity effect during the numerical magnitude comparison task indicates that the physical size of a number is automatically activated to facilitate or to interfere with the numerical magnitude comparison task.

Qi Dong, dongqi@bnu.edu.cn 


\section{Development of Automatic Processing of Numbers}

Most of the previous studies on the automatic processing of numbers have used adults such as college students as subjects. Not surprisingly, these studies consistently demonstrated that adults display automaticity in number processing. It is not clear, however, when children develop the ability to carry out automatic processing of numbers. Comparative work (Boysen \& Capaldi, 1993; Rumbaugh, Savage-Rumbaugh, \& Hegel, 1987) and infant research (e.g., Wynn, 1992; Xu, 2003; Xu \& Spelke, 2000) have shown that infants and chimps have a rudimentary number sense (see a review by Dehaene, Dehaene-Lambertz, \& Cohen, 1998). Studies of judgment of object quantity (e.g., Brannon \& Van de Walle, 2001; Bullock \& Gelman, 1977; Huntley-Fenner \& Cannon, 2000) have demonstrated that 2-year-old children could intentionally process quantity (number). Studies with actual number comparison tasks (Butterworth, 1999; Girelli et al., 2000; Rubinsten, Henik, Berger, \& Shahar-Shalev, 2002; Temple \& Posner, 1998) have also found that children as young as 5 years old showed intentional processing of numerical magnitude. However, research regarding the onset of automatic processing of numerical magnitude is limited.

To our knowledge, only five empirical studies thus far have provided information relevant to this question (Berch et al., 1999; Duncan \& McFarland, 1980; Girelli et al., 2000; Mussolin, 2002, cited in Noël et al., 2005; Rubinsten et al., 2002). Three of them used a Stroop-like paradigm. In a study of Italian children, Girelli et al. (2000) found that the size congruity effect started to emerge in the third grade (at a mean age of 8.4 years). First-grade Italian children did not show a size congruity effect when they were asked to compare the physical sizes of Arabic numerals and to ignore their numerical magnitude. Rubinsten et al. (2002) used Stroop-like tasks of numerical magnitude and physical size comparisons with a cross-sectional sample in Israel. They tested beginning first-grade students (mean age $=6.25$ years), students at the end of first grade (mean age $=7.32$ years), third-grade students (mean age $=$ 8.82 years), fifth-grade students (mean age $=11.0$ ), and undergraduate students (mean age $=22.8$ years). Results showed that the size congruity effect during physical size comparisons (indicating automatic processing of numerical magnitude) started to appear at the end of the first grade. Beginning first graders did not show such an effect, thus failing to provide evidence of automatic processing of numbers (termed "autonomous automatic processing" by the original authors, based on Tzelgov, Henik, Sneg, \& Baruch, 1996). In an unpublished study (Mussolin, 2002) described in a recent handbook chapter (Noël et al., 2005), second through fourth graders in Belgium were given a Stroop-like task that was somewhat different from the one used in Girelli et al. and Rubinsten et al. Results showed that second graders already showed the size congruity effect for single-digit pairs and for small two-digit pairs (numbers smaller than 50), but not for large two-digit pairs. In other words, among children in Belgium, automatic processing of small numerical magnitude emerged before second grade. This study further revealed that au- tomatic processing of larger numbers (those bigger than 50) emerged during the third grade.

In addition to the size congruity effect in Stroop-like tasks, other evidence has also been used to suggest automatic processing. For example, in a study of American children ranging from Grade 2 to Grade 8, Berch et al. (1999) looked for evidence of automatic processing as shown by the spatial-numerical association of response codes (SNARC) effect during a parity judgment task. The SNARC effect occurs when the left hand has an advantage in responding to tasks involving small(er) numbers, whereas the right hand has an advantage with tasks involving large(r) numbers (see, e.g., Dehaene et al., 1993; Fias et al., 1996). This spatial-numerical correspondence is deemed evidence for the left-to-right orientation of the mental number line. Therefore, its activation during a parity judgment task suggests automatic processing of the mental representation of numerical magnitude. Berch et al. (1999) found that the SNARC effect began to emerge at Grade 3.

Finally, it should be mentioned that an earlier study of American children (Duncan \& McFarland, 1980, Experiment 2) showed that even kindergartners showed a distance effect in identity judgment tasks. In that study, children were asked to judge whether two Arabic numerals were identical. Results showed that the smaller the numerical magnitude difference between the two numerals, the longer it took children to make the judgment. This finding of the distance effect has sometimes been cited as evidence of the early onset of automatic processing of numerical magnitude. However, the distance effect may not be a reliable indicator of automatic processing of numerical magnitude, because this effect has not been found to occur consistently for all subjects who should presumably display automatic processing of numbers (Noël et al., 2005). For example, third graders in the Girelli et al. (2000) study and all age groups in the Rubinsten et al. (2002) study during the physical size comparison tasks did not show the distance effect.

\section{The Present Study}

From the studies mentioned above, one could conclude that the early to middle elementary grades are the beginning point of automatic processing of numerical magnitude, at least with the Stroop-like paradigm and the SNARC effect. Theoretically, this makes sense, because much experience with number processing is probably needed before the process becomes automatic. It is not clear, however, whether the onset age discovered in the previous studies (Berch et al., 1999; Girelli et al., 2000; Mussolin, 2002; Rubinsten et al., 2002) can be generalized to other cultures, given the great cross-cultural variation in mathematical achievement and early mathematical acquisition. In the present study, we used Stroop-like tasks to investigate whether the onset of automatic processing had occurred for Chinese kindergartners.

According to previous research, Chinese children seem to have an advantage over their cross-cultural counterparts in several aspects of early numerical learning. First, Chinese digits have shorter pronunciation duration than digits in other languages, such as English (e.g., Chen \& Stevenson, 1988; Stigler, Lee, \& Stevenson, 1986). For example, 
Stigler et al. (1986) found that the average pronunciation duration of Chinese digits was $320 \mathrm{msec}$, whereas that of English digits was $420 \mathrm{msec}$. This advantage can have many consequences, because a greater number of digits can be stored in working memory. Chen and Stevenson (1988) found that as early as at preschool age, Chinese children already have a longer digit-span memory than American children. The difference in digit span for 4- to 6-year-olds was almost 1 digit (4.1 digits for American preschoolers and 5.0 digits for Chinese preschoolers; Chen \& Stevenson, 1988). We can speculate that shorter pronunciation duration may also partially account for Chinese students' superior performance in mental calculation (e.g., Stevenson et al., 1990) and Chinese adults' faster mental multiplication (Campbell \& Xue, 2001).

Second, the Chinese 10-based numbering system may also provide an advantage in early counting and mathematics (Ho \& Fuson, 1998; Miller, Kelly, \& Zhou, 2005; Miller, Smith, Zhu, \& Zhang, 1995). Counting in Chinese is simpler than in English because of its 10-based system: yi (one), er (two), san (three)..., shi (ten), shi-yi (tenone for 11), shi-er (ten-two for 12), shi-san (ten-three for 13)..., er-shi (two-ten for 20), er-shi-yi (two-ten-one for 21), er-shi-er (two-ten-two for 22), and so on. Miller et al. (1995) found that Chinese preschoolers made fewer mistakes in counting than their American counterparts.

Third, Chinese children also have greater exposure to numbers in daily life than English-speaking children, because the Chinese language uses numbers to name days of the week (i.e., xingqi-yi ["weekday one" for Monday], xingqi-er ["weekday two" for Tuesday], etc.) and months of the year (i.e., yi-yue ["one month" for January], er-yue ["two month" for February], etc.) (Kelly, Miller, Fang, \& Feng, 1999).

Finally, Chinese families' and preschools' early training (formal or informal teaching) in mathematics (cf. Huntsinger, Jose, Liaw, \& Ching, 1997; Miller et al., 2005) would also add to the linguistic advantages Chinese children already have. For example, in an observational study, Huntsinger et al. (1997) found that, in comparison with European Americans, Chinese preschoolers and kindergartners scored higher in a test of early mathematical abilities and Chinese parents gave more informal, direct mathematics instruction and more encouragement for mathematics-related activities (but also see Sy, Fang, \& Huntsinger, 2003, for different findings based on surveys and interviews). Taken together, the linguistic and cultural advantages of early numerical learning and exposure are likely to lead to an earlier onset of automatic processing.

The early advantages of number processing for Chinese children may also shed light on later differences in mathematical achievement. Previous cross-cultural research has shown that Chinese students displayed better performance in a wide variety of mathematical tasks (e.g., computation, measurement, estimation, word problems, operations, algebra, geometry, and trigonometry) than did their counterparts in other countries (e.g., Campbell \& Xue, 2001; Chen \& Stevenson, 1995; Stevenson, Chen, \& Lee, 1993; Stevenson et al., 1990). In contrast, according to recent reports from the TIMSS (Third Interna- tional Mathematics and Science Study, now renamed as Trends in International Mathematics and Science Study; Mullis, Martin, Gonzalez, \& Chrostowski, 2004; Mullis et al., 2000), eighth graders in the United States, Israel, and Italy had scores at or below the international average among about 40 countries (or regions). Although Mainland China was not part of the TIMSS, equivalent eighth graders in Hong Kong and Taiwan were top performers. Students in Belgium have shown great variations: Students in Flemish-speaking Belgium have been among the top performing children, scoring only behind East Asian students, whereas those in French-speaking Belgium were typically below the international average.

\section{METHOD}

\section{Subjects}

Thirty-six kindergartners (20 boys and 16 girls), with a mean age of 5 years 10 months (ranging from 5 years 4 months through 6 years 3 months), were recruited from four kindergartens in Beijing, China. These four kindergartens were purposely selected to cover a wide range of neighborhoods, including working- and middle-class neighborhoods. From each kindergarten, we randomly selected 8-10 children. All of the subjects were screened for vision using a Snellen visual acuity test (capital "E" in four different directions) and were determined to have normal vision.

\section{Apparatus}

The software DMDX, installed on a Dell notebook computer, was used to program the presentation of stimuli and to collect reaction time (RT) data.

\section{Tasks}

The subjects were presented two numbers on the screen. These numbers varied in physical size and numerical magnitude (see Materials, below). For the physical size comparison task, the subjects were asked to judge which number was bigger in physical size. For the numerical magnitude comparison task, they were asked to judge which number was bigger in numerical magnitude. The subjects were asked to press the left Shift key if they thought the left numeral was bigger than the right one in physical size (or numerical magnitude) and to press the right Shift key if they thought the right numeral was bigger than the left one.

\section{Materials}

Table 1 shows the stimuli used in the present study. These number pairs varied in level of congruence, numerical distance, and order. In terms of congruence level, each pair of numbers could be either congruent (i.e., one number is bigger than the other in both numerical magnitude and physical size) or incongruent (i.e., one number is bigger in numerical magnitude but smaller in physical size than the other). The neutral conditions had no variations either in physical size (in the case of numerical magnitude comparisons) or in numerical magnitude (in the case of physical size comparisons).

In terms of numerical distance, there were 6 levels, ranging from 1 to 6 . Following previous research (e.g., Dehaene \& Akhavein, 1995), numerical distances from 1 to 3 were grouped into the "smalldistance" category and those from 4 to 6 into the "large-distance" category. In addition, nine number pairs of the same numerical magnitude (i.e., numerical distance $=0$ ) were used for the neutral condition during the physical size comparison task.

Finally, each pair of numbers was presented in two different orders: once as shown in Table 1, and a second time in reverse order. This was to control for any possible order or position effects.

Together, there were 108 number pairs ( 3 pairs $\times 6$ levels of distance $\times 3$ congruence levels $\times 2$ orders) for both the numerical 
Table 1

Number Pairs Used As Stimuli for Both Numerical Magnitude and Physical Size Comparison Tasks

\begin{tabular}{|c|c|c|c|c|}
\hline \multirow[b]{2}{*}{$\begin{array}{c}\text { Numerical } \\
\text { Distance }\end{array}$} & \multicolumn{4}{|c|}{ Condition } \\
\hline & Congruent & Incongruent & $\begin{array}{c}\text { Neutral } \\
\text { (Numerical Magni- } \\
\text { tude Comparison) }\end{array}$ & $\begin{array}{c}\text { Neutral } \\
\text { (Physical Size } \\
\text { Comparison) }\end{array}$ \\
\hline 0 & - & - & - & $\begin{array}{l}1 \text { vs. } 1 \\
2 \text { vs. } 2 \\
9 \text { vs. } 9\end{array}$ \\
\hline 1 & $\begin{array}{l}1 \text { Vs. } 2 \\
4 \text { Vs. } 5 \\
8 \text { Vs. } 9\end{array}$ & $\begin{array}{l}1 \text { vs. } 2 \\
4 \text { vs. } 5 \\
8 \text { vs. } 9\end{array}$ & $\begin{array}{l}1 \text { vs. } 2 \\
4 \text { vs. } 5 \\
8 \text { vs. } 9\end{array}$ & - \\
\hline 2 & $\begin{array}{l}1 \text { vs. } 3 \\
4 \text { vs. } 6 \\
7 \text { Vs. } 9\end{array}$ & $\begin{array}{l}1 \text { vs. } 3 \\
4 \text { vs. } 6 \\
7 \text { vs. } 9\end{array}$ & $\begin{array}{l}1 \text { vs. } 3 \\
4 \text { vs. } 6 \\
7 \text { vs. } 9\end{array}$ & - \\
\hline 3 & $\begin{array}{l}1 \text { Vs. } 4 \\
3 \text { Vs. } 6 \\
6 \text { Vs. } 9\end{array}$ & $\begin{array}{l}1 \text { vs. } 4 \\
3 \text { vs. } 6 \\
6 \text { vs. } 9\end{array}$ & $\begin{array}{l}1 \text { vs. } 4 \\
3 \text { vs. } 6 \\
6 \text { vs. } 9\end{array}$ & - \\
\hline 4 & $\begin{array}{l}1 \text { vs. } 5 \\
3 \text { vs. } 7 \\
5 \text { vs. } 9\end{array}$ & $\begin{array}{l}1 \text { vs. } 5 \\
3 \text { vs. } 7 \\
5 \text { vs. } 9\end{array}$ & $\begin{array}{l}1 \text { vs. } 5 \\
3 \text { vs. } 7 \\
5 \text { vs. } 9\end{array}$ & - \\
\hline 5 & $\begin{array}{l}1 \text { Vs. } 6 \\
3 \text { VS. } 8 \\
4 \text { Vs. } 9\end{array}$ & $\begin{array}{l}1 \text { vs. } 6 \\
3 \text { vs. } 8 \\
4 \text { vs. } 9\end{array}$ & $\begin{array}{l}1 \text { vs. } 6 \\
3 \text { Vs. } 8 \\
4 \text { vs. } 9\end{array}$ & - \\
\hline 6 & $\begin{array}{l}1 \text { vs. } 7 \\
2 \text { vs. } 8 \\
3 \text { vs. } 9\end{array}$ & $\begin{array}{l}1 \text { VS. } 7 \\
2 \text { VS. } 8 \\
3 \text { vs. } 9\end{array}$ & $\begin{array}{l}1 \text { vs. } 7 \\
2 \text { vs. } 8 \\
3 \text { vs. } 9\end{array}$ & - \\
\hline
\end{tabular}

Note-Each number pair was used twice: once as shown in the table and a second time in reverse order. In addition, each of the number pairs in the neutral condition for the physical size comparison tasks was repeated once (in addition to the reverse-order presentation) in order to achieve the same number of items for each condition.

magnitude and the physical size comparison tasks. It should be noted that in order to create equivalence in experimental design, the number pairs for the neutral condition of the physical size comparison task were repeated once to yield an equivalent number of pairs as in the other conditions.

Each number pair ( $8 \mathrm{~cm}$ apart from each other) was presented at the center of the screen in white, against a black background. Two font sizes, in Arial font, were used for the numbers: 48 points (about $13 \mathrm{~mm}$ in height, $9 \mathrm{~mm}$ in width) and 96 points (about $27 \mathrm{~mm}$ in height, $18 \mathrm{~mm}$ in width). This $2: 1$ ratio between the two font sizes was the same as that used in Girelli et al. (2000).

\section{Procedure}

At the beginning of the experiment, the experimenter spent $10 \mathrm{~min}$ explaining the procedure to the child and making sure that the child felt comfortable in that setting. The child was asked to sit about $50 \mathrm{~cm}$ away from the computer screen. At the beginning of each trial, the symbols " ++ ," in font size 48, in Chinese Windows 2000, were used as fixation points presented at the center of the screen. The distance between the two "+" signs was $8 \mathrm{~cm}$. After 1,000 msec, a digit pair was presented in the same positions in which the fixation "+"s had been. The stimuli were kept on the screen until the child responded by pressing a key or until 5,000 msec had elapsed. During the practice period, the subjects were asked to make comparisons on 12 number pairs that varied in numerical distance, level of congruence, and order. Instructions emphasized both speed and accuracy.

The order of the two comparison tasks (numerical magnitude and physical size comparisons) was counterbalanced across subjects: Half of the subjects performed the numerical magnitude comparison tasks first and the other half the physical size comparison tasks first. There was a 5 -min break between the two comparison tasks. Within each task, the 108 number pairs were randomly presented in three sessions (36 pairs per session). Subjects had a 1-min rest between sessions.

\section{RESULTS}

\section{Physical Size Comparisons}

As mentioned in the introduction, the size congruity effect in the physical size comparison task would provide strong evidence of automatic processing of numerical magnitude. Two separate sets of analyses were conducted, because the neutral condition for this task had no numerical distance. The first set of analyses examined the size congruity effect without considering numerical distance, and the second set examined the distance effect and the size congruity effect and their interaction by using data from only the congruent and incongruent conditions. Figure 1 shows the results of the first set of analyses. Average median RTs were based on the median response latencies computed for correctresponse trials in each session for each subject. When the average RTs combined from the three conditions (ignoring the distance effect) were entered into a one-factor repeated measures ANOVA, we found a significant size congruity $\operatorname{effect}\left[F(2,70)=7.57, M S_{\mathrm{e}}=5,495.64, p<.01\right]$. Pairwise comparisons showed that RT was significantly longer for the incongruent condition than for the neutral condition and the congruent condition (see Figure 1, left panel). Analysis of error rates also revealed a main effect of size congruity $\left[F(2,70)=27.44, M S_{\mathrm{e}}=13.57, p<.001\right]$. Pairwise comparisons showed that the incongruent condition elicited greater errors than did the neutral and congruent conditions (see Figure 1, right panel). 

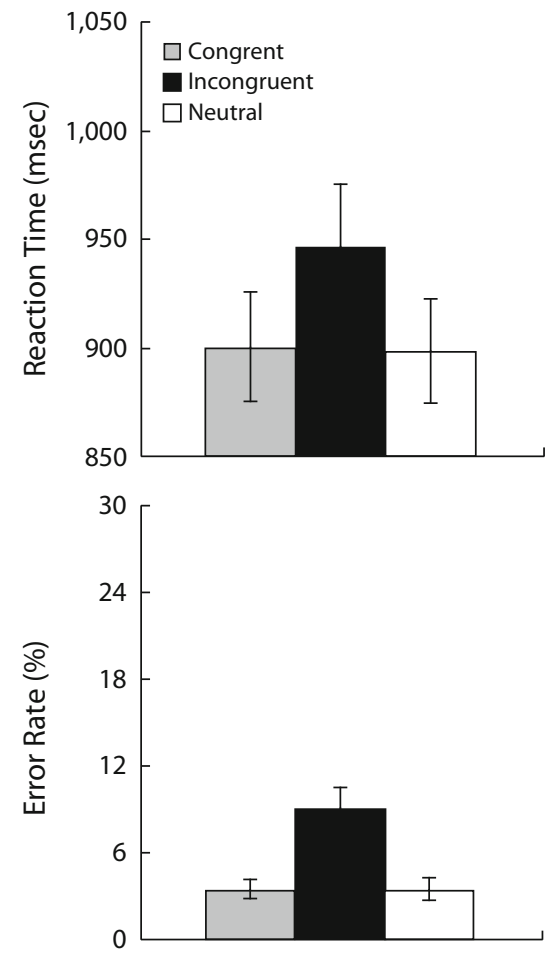

Figure 1. Average median reaction times (and standard errors) and mean error rates (and standard errors) for the physical size comparison tasks, averaged across various numerical distance trials.

The second repeated measures ANOVA had size congruity (congruent and incongruent) and numerical distance (small and large distance) as within-subjects factors. Results showed that, in addition to the main effect of size congruity as revealed by the first set of analyses $\left[F(1,35)=8.40, M S_{\mathrm{e}}=8,998.83, p<.01\right]$, there was a significant interaction between congruity and numerical distance $\left[F(1,35)=8.17, M S_{\mathrm{e}}=5,063.91, p<.01\right]$, but no main effect of numerical distance (see the top panel of Figure 2). Simple effects tests showed that the size congruity effect was significant only for the large-distance number pairs $\left[F(1,35)=19.98, M S_{\mathrm{e}}=5,063.91, p<\right.$ $.001]$, and the distance effect was significant only for the congruent condition $\left[F(1,35)=12.31, M S_{\mathrm{e}}=3,076.32\right.$, $p<.005]$. Analysis of error rates found only a significant main effect of size congruity $\left[F(1,35)=26.16, M S_{\mathrm{e}}=\right.$ $42.48, p<.001]$. (See the bottom panel of Figure 2.)

\section{Numerical Magnitude Comparisons}

Figure 3 (top panel) shows the RT (averages of medians) on the numerical magnitude comparison tasks by levels of congruence and numerical distance. A twofactor repeated measures ANOVA was conducted on average median latencies, with numerical distance (small vs. large distance) and congruity (neutral, congruent, and incongruent) as within-subjects factors. The main effects of size congruity and numerical distance were significant $\left[F(2,70)=72.34, M S_{\mathrm{e}}=19,241.87, p<.001\right.$, for the size congruity effect; $F(1,35)=23.37, M S_{\mathrm{e}}=28,947.59$, $p<.001$, for the numerical distance effect]. The interaction between congruity and numerical distance was also significant $\left[F(2,70)=3.97, M S_{\mathrm{e}}=15,136.94, p<.05\right]$. Further simple effects tests showed a significant size congruity effect for both the trials with small numerical distance $\left[F(2,70)=51.33, M S_{\mathrm{e}}=19,771.16, p<.001\right]$ and those with large numerical distance $[F(2,70)=29.93$, $\left.M S_{\mathrm{e}}=14,607.65, p<.001\right]$. Pairwise comparisons with Bonferroni adjustment at the level of .05 showed that, for both the small- and large-distance number pairs, RT was shortest for the congruent condition, followed by the neutral condition, and was longest for the incongruent condition. Simple effects tests also revealed a significant numerical distance effect for both the neutral condition $\left[F(1,35)=12.88, M S_{\mathrm{e}}=18,783.28, p<.005\right]$ and the incongruent condition $\left[F(1,35)=27.12, M S_{\mathrm{e}}=18,647.67\right.$, $p<.001]$, but not for the congruent condition.

The same analyses were conducted with error rates. Results on error rates mirrored those for RT. As Figure 3 (bottom panel) shows, there were significant main effects of size congruity $\left[F(2,70)=32.67, M S_{\mathrm{e}}=68.60, p<\right.$ $.001]$ and numerical distance $\left[F(1,35)=18.75, M S_{\mathrm{e}}=\right.$ $28.04, p<.001]$. Their interaction was also significant $\left[F(2,70)=4.23, M S_{\mathrm{e}}=42.39, p<.05\right]$. Further simple effects tests showed that, for both small- and large-distance number pairs, there were significant size congruity effects $\left[F(2,70)=27.37, M S_{\mathrm{e}}=63.68, p<.001\right.$, for small-
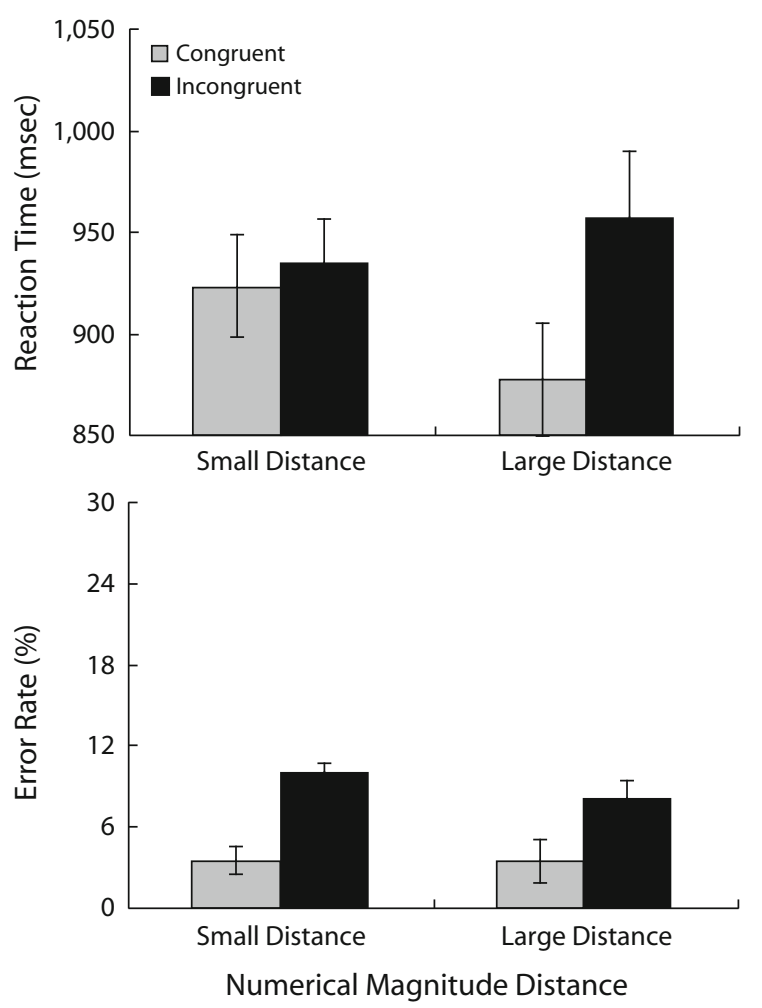

Figure 2. Average median reaction times (and standard errors) and mean error rates (and standard errors) for the physical size comparison tasks, analyzed by numerical distance. (The neutral condition had 0 numerical magnitude distance, and thus was not included in this analysis.) 
distance number pairs; $F(2,70)=14.32, M S_{\mathrm{e}}=47.31$, $p<.001$, for large-distance number pairs]. Pairwise comparisons showed that, for small-distance number pairs, the incongruent condition elicited more errors than the neutral and congruent conditions; for large-distance number pairs, both the incongruent and the neutral conditions elicited more errors than the congruent condition. Finally, a numerical distance effect was significant only for the incongruent condition $\left[F(1,35)=14.04, M S_{\mathrm{e}}=57.93, p<.001\right]$.

\section{DISCUSSION}

The goal of the present study was to investigate whether Chinese kindergartners had acquired automatic processing of numerical magnitude. Using Stroop-like tasks, we found that Chinese kindergartners showed a size congruity effect during the physical size comparison tasks. That is, they took significantly longer and made more mistakes when making physical size judgment under the incongruent condition than under the neutral and standard conditions (see Figure 1). Evidently, numerical magnitude information conveyed by the numbers interfered with the physical size comparison tasks. This result provided strong evidence of automatic processing of numerical magnitude by Chinese kindergartners.

When the data were analyzed by numerical distance, however, there was one exception to our general finding of significant congruity effects for the physical size comparison tasks: The congruity effect was not significant for the RT data for small-distance pairs (see Figure 2). There are no ready explanations for this exception, because it appeared only for RT, not for error rates, and only for small-
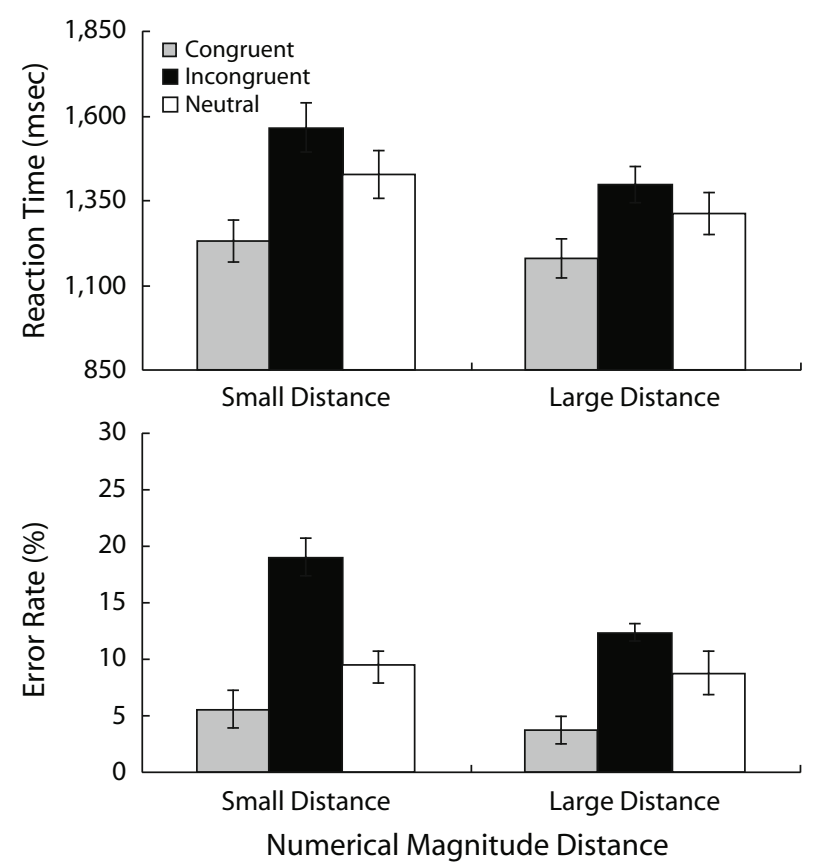

Figure 3. Average median reaction times (and standard errors) and mean error rates (and standard errors) for the numerical magnitude comparison tasks. distance trials. More research is needed to investigate the nature of this exception. It is of interest to note, however, that Schwarz and Heinze (1998) also reported that congruity effect depended on numerical distance. They found that, although congruity effect was significant for both smalland large-distance trials, it was somewhat greater for the former - a finding opposite to ours. They explained that small-distance trials were more difficult and took more time, thus allowing for more interference from numerical magnitude. That explanation would not apply in our finding because of the opposite pattern of interaction and because our exception was limited to the RT data.

Chinese kindergartners also consistently showed the expected congruity effect during the numerical magnitude comparison tasks. In other words, these children showed intentional processing of numerical values. Up till now, the youngest subjects tested with Stroop-like paradigms for evidence of intentional processing of numerical magnitude were first graders (Girelli et al., 2000; Rubinsten et al., 2002). Finally, insofar as the distance effect is a possible - although not reliable (see earlier discussion in the introduction; also see Noël et al., 2005) —indicator of automatic processing of numbers (e.g., mental line representation of numbers), our study also showed that the distance effect was evident across almost all tasks and trials.

Taken together, the results of this study and those of previous studies on Western children suggest that the onset of automatic processing of numerical magnitude in a Strooplike paradigm varies greatly across cultures. The onset ranges from at least as early as kindergarten in our study to as late as third grade, for Italians in Girelli et al. (2000), with Israeli children demonstrating automatic processing of numerical magnitude at the end of first grade (Rubinsten et al., 2002) and Belgian children showing the same thing sometime before second grade (Mussolin, 2002).

An obvious explanation for the cross-cultural variations in the onset of automatic processing lies in crosscultural differences in early mathematical acquisition. As mentioned in the introduction, Chinese children seem to have an advantage over their cross-cultural counterparts in several aspects of early numerical learning, such as digit pronunciation duration, number-naming system, daily exposure to numbers, and early mathematical training at home and preschool (e.g., Chen \& Stevenson, 1988; Ho \& Fuson, 1998; Miller et al., 1995; Stigler et al., 1986). These factors together (or individually) may have enhanced the acquisition of many features of numbers, including their relative numerical magnitudes. Early experiences in counting and simple addition may be the key to automatic processing of numbers.

Future research is needed to replicate our study as well as to make more direct comparisons across carefully matched samples from different cultures. Also needed are external indicators that the mathematical/numerical competence of these children (e.g., simple addition) is linked to children's level of automatic processing of numbers. Finally, research on specific cultural and social practices in preschool mathematical teaching would also help us to understand the factors that may lead to an early onset of automatic processing of numbers by Chinese children. 


\section{AUTHOR NOTE}

This study was supported by the National Pandeng Project (95) and the National 973 Project (2003CB716803). We thank Ellen Greenberger and three anonymous reviewers for their helpful comments and suggestions. Correspondence concerning this article should be addressed to Q. Dong, State Key Lab for Cognitive Neuroscience and Learning, Institute of Cognitive Neuroscience and Learning, Beijing Normal University, Beijing, China 100875 (e-mail: dongqi@bnu.edu.cn).

\section{REFERENCES}

Berch, D. B., Foley, E. J., Hill, R. J., \& Ryan, P. M. (1999). Extracting parity and magnitude from Arabic numerals: Developmental changes in number processing and mental representation. Journal of Experimental Child Psychology, 74, 286-308.

Besner, D., \& Coltheart, M. (1979). Ideographic and alphabetic processing in skilled reading of English. Neuropsychologia, 17, 467-472.

Boysen, S. T., \& CAPALDI, E. J. (1993) The development of numerical competence: Animal and human models. Hillsdale, NJ: Erlbaum.

Brannon, E. M., \& VAN DE Walle, G. A. (2001). The development of ordinal numerical competence in young children. Cognitive Psychology, 43, 53-81.

Bullock, M., \& Gelman, R. (1977). Numerical reasoning in young children: The ordering principle. Child Development, 48, 427-434.

Butterworth, B. (1999). The mathematical brain. London: Macmillan.

Campbell, J. I. D., \& Xue, Q. (2001). Cognitive arithmetic across cultures. Journal of Experimental Psychology: General, 130, 299-315.

Chen, C., \& Stevenson, H. W. (1988). Cross-linguistic differences in digit span of preschool children. Journal of Experimental Child Psychology, 46, 150-158.

Chen, C., \& Stevenson, H. W. (1995). Motivation and mathematics achievement: A comparative study of Asian-American, CaucasianAmerican, and East Asian high school students. Child Development, 66, 1215-1234.

DehaEnE, S. (1997). The number sense: How the mind creates mathematics. New York: Oxford University Press.

Dehaene, S., \& Akhavein, R. (1995). Attention, automaticity, and levels of representation in number processing. Journal of Experimental Psychology: Learning, Memory, \& Cognition, 21, 314-326.

Dehaene, S., Bossini, S., \& Giraux, P. (1993). The mental representation of parity and number magnitude. Journal of Experimental Psychology: General, 122, 371-396.

Dehaene, S., Dehaene-Lambertz, G., \& Cohen, L. (1998). Abstract representations of numbers in the animal and human brain. Trends in Neurosciences, 21, 355-361.

Duncan, E. M., \& MCFarland, C. E. (1980). Isolating the effects of symbolic distance and semantic congruity in comparative judgments: An additive-factors analysis. Memory \& Cognition, 8, 612-622.

Fias, W., Brysbaert, M., Geypens, F., \& D'Y dewalle, G. (1996). The importance of magnitude information in numerical processing: Evidence from the SNARC effect. Mathematical Cognition, 2, 95-110.

Girelli, L., Lucangeli, D., \& Butterworth, B. (2000). The development of automaticity in accessing number magnitude. Journal of Experimental Child Psychology, 76, 104-122.

HeNIK, A., \& Tzelgov, J. (1982). Is three greater than five: The relation between physical and semantic size in comparison tasks. Memory \& Cognition, 10, 389-395.

Ho, C. S.-H., \& Fuson, K. C. (1998). Children's knowledge of teen quantities as tens and ones: Comparisons of Chinese, British, and American kindergartners. Journal of Educational Psychology, 90, 536-544.

Huntley-Fenner, G., \& Cannon, E. (2000). Preschoolers' magnitude comparisons are mediated by a preverbal analog mechanism. Psychological Science, 11, 147-152.

Huntsinger, C. S., Jose, P. E., Liaw, F.-R., \& Ching, W.-D. (1997). Cultural differences in early mathematics learning: A comparison of Euro-American, Chinese-American, and Taiwan-Chinese families. International Journal of Behavioral Development, 21, 371-388.
Kelly, M. K., Miller, K. F., Fang, G., \& FenG, G. (1999). When days are numbered: Calendar structure and the development of calendar processing in English and Chinese. Journal of Experimental Child Psychology, 73, 289-314.

MilleR, K. F., Kelly, M., \& ZhOU, X. (2005). Learning mathematics in China and the United States: Cross-cultural insights into the nature and course of preschool mathematical development. In J. I. D. Campbell (Ed.), Handbook of mathematical cognition (pp. 163-177). New York: Psychology Press.

Miller, K. F., Smith, C. M., Zhu, J., \& Zhang, H. (1995). Preschool origins of cross-national differences in mathematical competence: The role of number-naming systems. Psychological Science, 6, 56-60.

Moyer, R. S., \& Landauer, T. K. (1967). The time required for judgments of numerical inequality. Nature, 215, 1519-1520.

Mullis, I. V. S., Martin, M. O., Gonzalez, E. J., \& Chrostowski, S. J. (2004). TIMSS 2003 international mathematics report: Findings from IEA's trends in international mathematics and science study at the fourth and eighth grades. Chestnut Hill, MA: Boston College, Lynch School of Education.

Mullis, I. V. S., Martin, M. O., Gonzalez, E. J., Gregory, K. D., Garden, R. A., O'ConNor, K. M., ET AL. (2000). TIMSS 1999 international mathematics report. Chestnut Hill, MA: Boston College, Lynch School of Education.

Mussolin, C. (2002). L'automaticité de l'accés à la représentation numérique chez l'enfant. Unpublished master's thesis, Université Catholique de Louvain, Belgium.

NoËL, M.-P., Rousselle, L., \& Mussolin, C. (2005). Magnitude representation in children: Its development and dysfunction. In J. I. D. Campbell (Ed.), Handbook of mathematical cognition (pp. 179-195). New York: Psychology Press.

Rubinsten, O., Henik, A., Berger, A., \& Shahar-Shalev, S. (2002). The development of internal representations of magnitude and their association with Arabic numerals. Journal of Experimental Child Psychology, 81, 74-92.

Rumbaugh, D. M., Savage-Rumbaugh, S., \& Hegel, M. T. (1987). Summation in the chimpanzee (Pan troglodytes). Journal of Experimental Psychology: Animal Behavior Processes, 13, 107-115.

SCHWARZ, W., \& HeINZE, H. J. (1998). On the interaction of numerical and size information in digit comparison: A behavioral and eventrelated potential study. Neuropsychologia, 36, 1167-1179.

Stevenson, H. W., Chen, C., \& Lee, S.-Y. (1993). Mathematics achievement of Chinese, Japanese, and American children: Ten years later. Science, 259, 53-58.

Stevenson, H. W., Lee, S.-Y., Chen, C., Lummis, M., Stigler, J., FAN, L., \& GE, F. (1990). Mathematics achievement of children in China and the United States. Child Development, 61, 1053-1066.

Stigler, J. W., Lee, S.-Y., \& Stevenson, H. W. (1986). Digit memory in Chinese and English: Evidence for a temporally limited store. Cognition, 23, 1-20.

Sy, S. R., FANG, G., \& Huntsinger, C. S. (2003). Formal instruction and kindergarten achievement in China and the United States. Journal of Psychology in Chinese Societies, 4, 247-267.

Temple, E., \& Posner, M. I. (1998). Brain mechanisms of quantity are similar in 5-year-olds and adults. Proceedings of the National Academy of Sciences, 95, 7836-7841.

Tzelgov, J., HeniK, A., Sneg, R., \& Baruch, O. (1996). Unintentional reading via the phonological route: The Stroop effect with cross-strip homophones. Journal of Experimental Psychology: Learning, Memory, \& Cognition, 22, 336-349.

Tzelgov, J., Meyer, J., \& HeniK, A. (1992). Automatic and intentional processing of numerical information. Journal of Experimental Psychology: Learning, Memory, \& Cognition, 18, 166-179.

WynN, K. (1992). Addition and subtraction by human infants. Nature, 358, 749-750

XU, F. (2003). Numerosity discrimination in infants: Evidence for two systems of representations. Cognition, 89, B15-B25.

Xu, F., \& Spelke, E. S. (2000). Large number discrimination in 6month-old infants. Cognition, 74, B1-B11.

(Manuscript received July 18, 2005; revision accepted for publication December 1, 2005.) 